\title{
Eye complaints in the office environment: precorneal tear film integrity influenced by eye blinking efficiency
}

\author{
P Wolkoff, J K Nøigaard, P Troiano, B Piccoli
}

Occup Environ Med 2005;62:4-12. doi: 10.1136/oem.2004.016030

To achieve a common base for understanding work related eye complaints in the office environment, it is necessary to merge approaches from indoor air science, occupational health, and ophthalmology. Based on database searches, it is concluded that precorneal tear film (PTF) alteration leads to eye complaints that may be caused by: (1) thermal factors (low relative humidity; high room temperature); (2) demanding task content (attention decreases blinking and widens the exposed ocular surface area); and (3) individual characteristics (for example, tear film alterations, blinking anomalies, gland dysfunctions, and use of contact lenses). These factors and conditions are able to progressively increase water evaporation and faster thinning of the PTF, which causes dryness and dry spot formation on the cornea, possibly followed by corneal and conjunctiva epithelial alterations and eye complaints. Another possible cause of eye complaints is certain irritating chemical compounds, in addition to oxidation mixtures that are formed in reactions between ozone and unsaturated organic compounds (alkenes). The effect may be exacerbated by low relative humidity.

See end of article for authors' affiliations

Correspondence to: Prof. P Wolkoff, National Institute of Occupational Health, Copenhagen, Denmark; pwo@ami.dk

Accepted 24 August 2004
E ye complaints, such as burning, dryness, gritty, itchy, and stinging feeling, scratchi- ness, soreness, blurry vision, strain, etc ("eye irritation"), are commonly reported symptoms in epidemiological studies of the indoor environment. ${ }^{12}$ These symptoms, in particular perceived "dry eyes" and related ocular surface effects (also called "ocular discomfort"), are major eye complaints treated by ophthalmologists. ${ }^{3-5}$ Indeed, it has been concluded in one review that, "It was unclear just how often one should expect symptom-free individuals". ${ }^{6}$ "Tired and strained eyes" have been reported to be the most common cause of disruption of office work, followed by mental fatigue and headache ${ }^{7}$ (cf. Begley et $\left.a^{8}\right)^{8}$. Associations between complaints and work duration have been identified in visual display unit (VDU) workers. ${ }^{9}{ }^{10}$ However, the pathogenesis of eye complaints is not well understood, mainly because there is no common terminology of the numerous kinds of symptoms as well as no consensus on the exposure evaluation procedures.

Eye complaints such as "dry eyes", have been associated with occupational factors, such as office equipment, ${ }^{11}$ and indoor air pollution. ${ }^{12-14}$
Such eye complaints may be caused by alteration of the precorneal tear film (PTF) that protects the outer eye from environmental factors. "Alteration" in this paper is the process of thinning of the PTF followed by rupture (that is, PTF break-up) due to environmental conditions-mainly thermal factors (high room temperature, low relative humidity $(\mathrm{RH})$ ), and indoor pollutants.

The stability of the PTF is inter alia influenced by individual physiological characteristics such as the composition of (1) the outer lipid layer (LL), (2) the underlying water layer, and (3) the innermost layer of mucin. ${ }^{15}$ Clinical tests to evaluate the PTF integrity and stability are the "break-up time" (BUT, sec) and the thickness $(\mu \mathrm{m}) .{ }^{16}{ }^{17}$ Eye blinking and tear secretion appear to be essential for the maintenance of a "normal" PTF,, 151819 and are also important for achieving constant high quality retinal images. ${ }^{2021}$

It is important to understand the physiological factors that are responsible for eye complaints in office environments with specific attention to VDU work, for example, in which the visual and cognitive demand can be high. In this regard, it is worth noting that "eye complaints" or "occupational asthenopia" among office workers have a multifactorial origin, including the possible overloading of accommodation and convergence caused by prolonged near work. ${ }^{22}$

The causes of eye symptoms remain unknown. They could be the result of PTF effects such as dryness derived from: (1) an increased water loss by evaporation due to thermal and/or other indoor environmental factors, (2) an altered PTF (APTF) caused by hyposecretion of tear fluids (because of gland dysfunctions), or (3) a trigeminal nerve ending stimulation by indoor pollution facilitated by an APTF.

The purpose of this review is twofold: firstly, to merge approaches derived from indoor air science, occupational health, and ophthalmology in order to achieve a common base for understanding work related eye complaints in the office environment; and secondly, to analyse if, and eventually how, in office workers:

- Blinking alterations could play a role in increased PTF alterations.

Abbreviations: APTF, altered precorneal tear film; BF, blinking frequency; BUT, break-up time; $\mathrm{CL}$, contact lens; LL, lipid layer; OS, ocular surface; PTF, precorneal tear film; $\mathrm{RH}$, relative humidity; VDU, visual display unit; $\mathrm{VOC}$, volatile organic compound 


\section{Main messages}

- To avoid ocular surface dryness (that is, precorneal tear film break-ups and corneal dry spots), it is important, in particular during demanding visual tasking, for example, VDU work, with specific regard to computer design activities such as CAD-CAM, CAT, etc, to depress water evaporation by allowing sufficiently high periocular relative humidity.

- Normal blinking and a small exposed ocular surface minimise water loss and early rupture of the precorneal tear film.

- Sources of volatile chemically reactive compounds should be kept under surveillance, in particular in the presence of ozone.

- In low humidity environments, where highly demanding visual/cognitive work is carried out, subjects suffering from ocular surface pathologies and/or contact lens wearers should be considered as more "susceptible". These individuals should be included in specific health surveillance programmes according to Council Directive 90/270/EEC.

- PTF alterations are associated with some specific environmental factors, such as low RH and/or high room temperature and air velocity.

- Indoor air pollution could cause PTF alterations and/or eye symptomatology.

\section{METHODS}

Researchers with experience in indoor air science, occupational health, and ophthalmology have reviewed the indoor climate literature about eye irritation and related eye symptoms/signs. The search strategy also included physiology of the outer eye: precorneal tear film, tear physiology, blink frequency/rate, break-up time, dehydration, dry eyes, dry spots, epithelial damage of conjunctiva, gland (meibomian, lacrimal, goblet) dysfunctions, and objective eye sign measures. Search of the epidemiological literature focused on associations between eye irritation symptoms/signs and indoor air pollution, including human exposure studies with indoor pollutants. Exclusion criteria were within refractive related complaints, work related musculoskeletal disorders, lighting, and psychosocial and psychological factors. The search was carried out using the following databases: PubMed/Medline (from 1990) and ISI Web of Knowledge (from 2000).

\section{FACTORS INFLUENCING EYE BLINKING Distribution of the PTF}

The PTF is essential in defending the ocular surface (OS) from environmental exposure, thus minimising injury. The distribution of the PTF is a coating process achieved by a narrowing of the palpebral fissure, proceeding from the lateral canthus towards the medial canthus during each blink. ${ }^{15}{ }^{23}$ The PTF integrity depends on the complex interaction of the blink process with tear composition. Blinking is also important in mechanically removing deposited particles and cellular debris. ${ }^{24} 25$

\section{Blinking types and dependencies}

Blinking can be classified into three categories. ${ }^{26}$ Voluntary blinking is the result of a conscious decision to close and open the eyelids. Involuntary (spontaneous) blinking, however, occurs without any external stimulus and at a fairly constant rate; this probably arises from the activity of a central "blink generator" in the brain, although the neural basis in detail is not fully understood (cf. Acosta et a ${ }^{27}$ ). Reflex blinking is a rapid closure movement of short duration as a response to a variety of external stimuli, mainly visual or ocular, but also auditory, cognitive, trigeminal, or visual stimuli, as well as other motor behaviours. Reflex blinking is dominated by trigeminal stimulation. ${ }^{26}$ The major determinants of the blinking frequency (BF) at rest are extrinsic factors, such as dehydration as a result of water loss, arising from local PTF conditions of the cornea and conjunctiva and stimulation of their sensory receptors caused by task related and environmental factors. ${ }^{27-29}$ Visual tasks, temperature, $\mathrm{RH}$, and lighting conditions also influence the BF (cf. Wolkoff et $\left.a l^{11}\right)$.

About $80 \%$ of blinks are complete, in which the descending upper eyelid covers more than two thirds of the cornea; about $18 \%$ are incomplete, in which the descending eyelid covers less than two thirds of the cornea; less than $2 \%$ are twitch blinking (flutter). ${ }^{30-32}$ BFs are individual with mean frequencies from less than 2-3 up to 20-30 blinks/min, but typically about $12-20$ blinks/min if the subject is at rest under neutral environmental conditions. ${ }^{26}{ }^{33-35}$ However, blinking is influenced inter alia by a number of individual and task related factors, for example, attention, task complexity, gaze direction, emotional state, and verbalisation ${ }^{36}$ (see table 1). For example, visual tasking-that is, work difficulty, complexity, and cognitive overload, lowers the BF. There appears to be an inverse relation between difficulty of task and BF. In addition, visual tasking competes with other external influences and stimuli such as high air velocity, and overriding may occur. ${ }^{27}{ }^{35}$ Conversation on the other hand may result in some increase of the BF. The latter is usually highest for difficult tasks (see table 1).

It has to be noted, however, that each subject has his/her own specific "blink pattern" with intra- and inter-individual daily variability of varying degree..$^{33} 35$ The daily variation of the BF depends on a number of visual and environmental conditions, which may positively and negatively contribute to the summed BF. ${ }^{11} 38$

In order to compensate for the deterioration of visual quality by APTF, BF is likely to be lowered. The price to be paid for the maintenance of such a quality could be one of the possible contributions to the development of ocular/visual disturbances $\left(\mathrm{cf}\right.$. Piccoli ${ }^{22}$ ). Sustained BFs above the higher peaks of the normal range could indicate either environmentally induced eye irritation or a highly aroused mental state in normal subjects. ${ }^{35}$

\section{EFFECTS ALTERING THE PTF Water loss/dehydration of the PTF (aqueous tear deficiency)}

Evaporation of water molecules from the intact PTF occurs by internal diffusion (that is, LL acts as a barrier) to the ambient air, when the RH is lower than $100 \%$ - that is, driven by the "evaporation driving force". ${ }^{39}$ External diffusion (no barrier as opposed to internal diffusion) will dominate the water evaporation from an APTF. High air velocity will enhance the evaporation of water, resulting in a faster temperature decrease, especially at the cornea (see below). High air velocity $(>1 \mathrm{~m} / \mathrm{s})$ may result in a slight increase of BF during resting conditions, ${ }^{28}$ this, however, can be overruled by visual tasking; for example, game playing or VDU work. ${ }^{27}$ In the latter case, VDU work becomes a special case in which BF decreases, becoming consistently overdue as a result of cognitive functions (effort). This causes BF to fall below "average" and possibly a widening of the exposed cornea, thus resulting in an increased water evaporation, possibly 
Table 1 Effects on blink frequency as function of mental and visual tasks

\begin{tabular}{|c|c|c|}
\hline \multicolumn{2}{|c|}{ Experimental design and method } & \multirow[b]{2}{*}{ Blink frequency changes } \\
\hline $\begin{array}{l}\text { Men/women } \\
\text { (age, years), design }\end{array}$ & $\begin{array}{l}\text { Method, and time of } \\
\text { observation, } \min \end{array}$ & \\
\hline $\begin{array}{l}27 / 22(19-25) \text {, task and } \\
\text { gaze were randomly } \\
\text { allocated to subjects }{ }^{142}\end{array}$ & Direct counting, 2 & $\begin{array}{l}\text { Highest during conversation } \\
\text { Lowest during visual acuity (visual task) and the reduction is proportional to the attentional } \\
\text { demand of mental task } \\
\text { Difficulty of task had no influence on BF. However, BF depended on the position of the gaze }\end{array}$ \\
\hline $\begin{array}{l}70 / 80(5-87), \text { fixed order } \\
\text { of tasks }\end{array}$ & Videotaping, 21/2 & $\begin{array}{l}\text { High at conversation } \\
\text { Low during reading } \\
\text { Most common pattern of } \mathrm{BF} \text { in decreasing order was: conversation }<\text { rest }<\text { reading } \\
\text { Conclusion: } \mathrm{BF} \text { does not depend on ocular conditions, age, and wear }\end{array}$ \\
\hline $7 / 1(21-29)^{144}$ & $\begin{array}{l}\text { Measure of biopotential } \\
\text { at canthi }\end{array}$ & Significant decrease while TRACON work became more difficult \\
\hline $32 / 0(18-32)^{145}$ & $\begin{array}{l}\text { Measure of biopotential } \\
\text { at canthi, } 40\end{array}$ & $\begin{array}{l}\text { Blink duration and eyelid closure increased during task } \\
\text { An increase when the attentional process wane }\end{array}$ \\
\hline 22 students $^{146}$ & $\begin{array}{l}\text { Measure of biopotential } \\
\text { at canthi }\end{array}$ & $\begin{array}{l}\text { Significantly higher for a difficult task than an easy arithmetic task } \\
\text { Unchanged if the task was a letter search }\end{array}$ \\
\hline $29 / 20(22-50)^{147}$ & $\begin{array}{l}\text { Measure of biopotential } \\
\text { at canthi, } 3\end{array}$ & $\begin{array}{l}\text { Reduction at visual task, but an increase during conversation } \\
\text { Substantial increase at mental loading and while memorisation } \\
\text { Dopamine activity correlates directly with BF }\end{array}$ \\
\hline $16 / 0$ (students) $^{148}$ & $\begin{array}{l}\text { Measure of biopotential } \\
\text { at canthi, } 32\end{array}$ & Lower at visual task than during auditory tasks, also lower blink duration \\
\hline 20 students $^{1 / 49}$ & $\begin{array}{l}\text { Counting from television } \\
\text { screen }\end{array}$ & $\begin{array}{l}\text { An increase at difficult problems, significant differences between easy and difficult tasks } \\
\text { Internal stimuli may cause an increase, however only for easy tasks }\end{array}$ \\
\hline $27 / 14(20-42)^{150}$ & $\begin{array}{l}\text { Measure of biopotential } \\
\text { at canthi }\end{array}$ & $\begin{array}{l}\text { High at conversation, oral proverb interpretation, memory recitation } \\
\text { Low at proverb interpretation by reading a card }\end{array}$ \\
\hline $0 / 24(19-20)^{151}$ & $\begin{array}{l}\text { Measure of biopotential } \\
\text { at canthi }\end{array}$ & Data suggest an inverse relation between $\mathrm{BF}$ and visual task difficulty \\
\hline
\end{tabular}

followed by ruptures as a result of an APTF (cf. Golding et al ${ }^{40}$ and Miller et $a l^{41}$ ).

High $\mathrm{RH}$ reduces the $\mathrm{BF}^{42}{ }^{43}$ and an inverse proportionality regarding the ambient temperature has been observed. ${ }^{43}$ In addition, BUT was found to be lower in dry and warm environments compared to that of cold and humid environments $^{44}$ ( $\mathrm{cf}$. Berke $\mathrm{e}^{45}$ ); similarly, BUT was found to be inversely associated with increasing temperature among female nurses. ${ }^{46}$ This, of course, may possibly have been the result of an associated lower RH. The findings support the fact that APTF recurs under conditions favouring water loss. For example, it was found in a crossover study in public office buildings that a $1{ }^{\circ} \mathrm{C}$ decrease in temperature (within 22$26^{\circ} \mathrm{C}$ ) correlated with $19 \%$ decrease of the mean value in severity of eye complains (dry, itching, irritated). ${ }^{47}$ The mean prevalence for eye complaints increased slightly from morning to afternoon in public buildings, 8889 which is compatible with the observation that the LL thickness decreases during an office working day, ${ }^{50}$ concurrently with an increase of the room temperature. ${ }^{51}$ Note that the intensity of symptoms among dry eye patients is significantly greater in the evening than in the morning. ${ }^{8}$ It is of note that BUT similarly decreases and eye irritation increases over time under controlled climate conditions of clean air. ${ }^{52}$

Increased water evaporation from the OS results in cooling of the cornea and the lids, in particular during condition of low BF, low RH, and upgaze, or combinations thereof. ${ }^{53} 54$ Rapid cooling appears to be related to APTF, possibly due to its inability to retard the evaporation, thus stimulating blinking. ${ }^{55}$ For example, subjects whose cornea showed a slower cooling following a blink showed a greater capacity to avoid blinking for a prolonged period of time. ${ }^{56}$ On the other hand, the corneal temperature in dry eye patients varied less than that in normal control subjects, possibly because of less water evaporation from the PTF of dry eye patients. ${ }^{54}$ This agrees with the proposal that thermosensitive cold fibres in the cornea may initiate reflex blinking by cooling. ${ }^{32}{ }^{54}$ Stimuli which modify neural activity in the sensory fibres of the cornea and conjunctiva, such as increased evaporation or additional humidification, may change the involuntary BF. Evaporation of water has also been reported to increase in dry eye patients, accounting for the majority of the water loss, ${ }^{57}$ partly because it "pulls ahead" the tear secretion. ${ }^{58}$ In addition, dry eye patients generally have lower BUTs and

Table 2 Some specific symptoms and their hypothesised pathogenesis

\begin{tabular}{|c|c|}
\hline Symptom & Proposed (hypothesised) cause(s) \\
\hline \multicolumn{2}{|l|}{ Dry eyes } \\
\hline Gritty and sandy & $\begin{array}{l}\text { Air exposed nerve endings in the microvilli layer of epithelium, where the mucin layer has been ruptured, } \\
\text { exposing patches of bare microvilli and nerve endings } \mathrm{s}^{152}\end{array}$ \\
\hline Fuzzy vision & $\begin{array}{l}\text { Meibomitis } \\
\text { Allergic conjunctivitis }{ }^{66139} \\
\text { The mucin layer is intact, but the water layer over the mucin layer breaks up into small islands that distort the } \\
\text { transfer of light }\end{array}$ \\
\hline \multicolumn{2}{|r|}{ 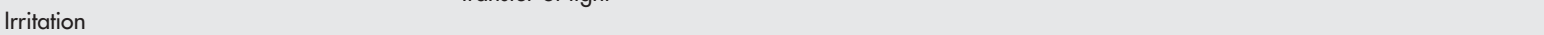 } \\
\hline Stinging, burning, pain & $\begin{array}{l}\text { Break up of PTF, possibly followed by chemical stimulation, including increased osmolarity due to evaporation. } \\
\text { This may stimulate nociceptors, which are sensitive to chemical and mechanical stimuli } 123\end{array}$ \\
\hline Burning, irritation, tearing, dryness & Upgaze, glare, small font, flicker ${ }^{118}$ \\
\hline Ache and strain & Near work, lens flipper, mixed astigmatism conditions (accommodative and vengeance stress) \\
\hline
\end{tabular}


higher surface tension of the tear liquid in contrast to normal eyes. ${ }^{59}$

\section{Use of contact lenses}

Dry eyes, redness, and grittiness are common complaints among contact lens (CL) wearers and are reported more frequently than among non-wearers; ${ }^{35}{ }^{60-65}$ in addition, loss of optical qualities (for example, blurred vision) is often reported. ${ }^{21}{ }^{66}$ The symptoms are more frequent in the evening than during the day. ${ }^{67}$

Indeed, it has to be noted that, once positioned, a CL separates coarsely the PTF tissue into a pre-lens and a postlens fraction, producing two important structural and functional modifications: the disappearance of mucine in the pre-lens fraction and the disappearance of the LL in the post-lens fraction. Recently this has been objectively evaluated by interpherometry investigations. ${ }^{68}$ CL wear compromises the PTF stability, and the disappearance of the LL in the post-lens fraction, which causes an increase of water evaporation, ${ }^{69-72}$ followed by a corresponding increase of the physiological osmolarity, responsible for OS damage. ${ }^{65}$ 73-75 $^{3}$ These PTF alterations are consistent with the symptoms and disturbances reported in the occupational health and safety and indoor climate literature, and support the fact that some CL wearers are more susceptible than non-wearers to some specific adverse environmental conditions (cf. Wolkoff et $\left.a l^{11}\right)$, including enhanced sensitivity to low temperature and RH. ${ }^{69} 76$

Moreover, CL wearers have different PTF characteristics compared to that of non-CL wearers or intolerant CL wearers. ${ }^{77}$ For example, in a study of soft-CL wearers divided into complete and incomplete blinkers, the incomplete blinking group showed a significant decrease in the dehydration level of the inferior part of the soft lenses compared to that of the control group with low incomplete blinking. Consistent fluorescein staining of the inferior part of the cornea was observed in the incomplete blinking group. This group also suffered more from discomfort and dryness, including more lens deposits, ${ }^{78}$ ( $\mathrm{cf}$. Abelson and Holly ${ }^{30}$ ). It is of note that BUT was the same in both groups.

\section{CONSEQUENCES OF BLINKING ANOMALIES Ruptures of the PTF}

The main consequence of incomplete and reduced $\mathrm{BF}$ is a significant increase of APTF. ${ }^{45} 6479$ APTF films alter faster and/or more severely than normal ones. ${ }^{2345708081}$ APTF consequent to a incomplete blinking is more prone to ruptures (staining areas into the "inferior paralimbal" part of the cornea). There are corneal sub-regions that are much thinner than others. For example, more than 10-fold reduction of the PTF thickness in 40 seconds has been modelled near the inferior lid. ${ }^{23}$ A critical thickness of PTF of $7 \mu \mathrm{m}$ has been estimated to result in moderate to severe ruptures. ${ }^{70}$ Deliberate forceful blinking, on the other hand, was found to increase the thickness of PTF. ${ }^{82}$

In some subjects PTF thinning leads to its rupture before the next blink, and dry spots are thus formed, exposing the bare corneal and bulbar conjunctival epithelium to, for example, chemical pollutants for a limited period. ${ }^{83}$ Indeed, in normal subjects, the BUT exceeds the interval between blinks-that is, the PTF permanently covers largely all the cornea. Incomplete blinking results in less effective redistribution of the PTF; this results in more frequent and wider ruptures (that is, more leaky), in particular over the inferior part of the cornea (that is, where the upper eyelid reaches its lowest descent point). ${ }^{83-88}$

The water loss may be fourfold faster from an APTF. ${ }^{53}$ It has been proposed that enhanced thinning is preceded by evaporation. ${ }^{41}$ Note that BF and BUT are weakly associated, ${ }^{32}$ even though BUT and water loss are not necessarily inversely correlated in normal subjects, ${ }^{89}$ but are in dry eye patients. ${ }^{90}$ In addition, the evaporation is increased in dry eyes which accounts for the majority of water loss, ${ }^{57} 9192$ this is possibly a result of a thin PTF. ${ }^{69} 93$ PTF not only becomes thinner at reduced $\mathrm{BF}$, but also by a large exposed OS. VDU work or playing video games result in reduced $\mathrm{BF}$, an enlarged exposed OS area, and a significantly greater water loss than during relaxed conditions or downward gaze (cf. table 1 in Wolkoff $e \mathrm{al}^{11}$ ). These circumstances can finally result in a reduced BUT. ${ }^{45}$ Thus, the combined effects of reduced BF, incomplete blinking, and wider Os lead to water loss, which may not be physiologically compensated for.

\section{Hyperosmolarity of the PTF}

PTF production (in terms of "quality" and "quantity"), lacrimal duct run-off, and water loss from the PTF are balanced by the homoeostatic mechanism to control and maintain the OS integrity. ${ }^{94}$ Tear hyperosmolarity (that is, above the physiological level of osmolarity, which is approx. $310 \mathrm{mOsm} / \mathrm{l}$ ) is in part a consequence of the high rates of water loss and inadequate tear secretion from the lacrimal glands. ${ }^{95}$ The rate of water evaporation and osmolarity were found to be positively correlated, and both have also been found to be positively related to APTF, ${ }^{96}$ so the effect of evaporation on tear osmolarity is significant. ${ }^{94}$

It has been modelled how important the function of the LL, produced by the meibomian glands, is in maintaining normal PTF composition. In fact, an alteration of LL produces on PTF a domino effect consisting of higher water evaporation, increase of osmolarity, goblet cell sufferance, glycocalix disorder, and finally, dry spot formation. ${ }^{18} 97$ This is particularly evident in patients with meibomian gland dysfunctions, because in these patients the highest correlation between osmolarity and lipid function was found. Those with a high lipid volume were better at maintaining a low evaporation rate than those with a low lipid function - that is, a thin LL. ${ }^{94}$

\section{EFFECTS OF INDOOR POLLUTION (VAPOURS AND PARTICLES) ON THE PTF}

The PTF contains proteins with antibacterial activity, nutrients, lubricants, vitamins, and other substances to protect the OS against damage caused by, for example, microorganisms, ozone, and radicals. ${ }^{34} 9899$ It has been inferred, but without further specification, that environmental factors may influence the PTF stability. ${ }^{35} 87$

It has previously been postulated that (prolonged) exposure to environmental pollution might cause eye complaints. ${ }^{12-14}$ In particular, lipophilic and/or surface active pollutants (for example, detergents) have been hypothesised to cause thinning of PTF, finally resulting in ruptures and epithelial alteration of conjunctiva, called "pollution keratoconjunctivitis". ${ }^{14}$ According to present knowledge, exposure to lipophilic or hydrophilic indoor volatile organic compounds (VOCs) may alter the PTF at industrial concentration levels. APTF has been observed for exposure to decane ${ }^{100}$ and propylene glycol, ${ }^{101}$ representative of a lipophilic and a hydrophilic VOC, respectively. However, a number of glycol ethers and esters have not been shown to cause APTF at industrial concentration levels. ${ }^{102-105}$ Similarly, a mixture of 22 different VOCs dominated by butyl acetate and toluene did not alter BUT at a total level of $24 \mathrm{mg} / \mathrm{m}^{3}{ }^{106}$ Office environment VOC concentrations are generally 3-4 orders of magnitude lower than industrial levels or occupational exposure limits. Further, there is no convincing evidence that either common (chemically non-reactive; for example, toluene, butyl acetate) VOCs or particles at typical indoor levels result in an APTF, and are able to cause eye complaints (cf. Wolkoff et $a l_{,}{ }^{11}$ Schneider et $a l^{107}$ ). At present, it appears 
that oxidation products from the reaction between certain unsaturated VOCs (that is, alkenes), like monoterpenes, that are used in household products as solvents or fragrances (for example, in air fresheners) and ozone may contribute to eye irritation, ${ }^{37}$ in addition to the well known eye irritants, for example, formaldehyde and acrolein. ${ }^{108}$

Smokers show a higher prevalence of eye complaints than non-smokers. ${ }^{2}$ In addition, BUT is lower among smokers compared with non-smokers, thus indicating that tobacco smoke causes APTF. ${ }^{109}$ Similarly, people living and working in more polluted environments have lower BUTs than people from less polluted areas, ${ }^{12}$ inferring that urban pollution causes APTF. A decrease of self-reported BUT has been attributed to certain VOC emissions from degraded polyvinyl chloride flooring, in particular 2-ethylhexanol. ${ }^{110}$ However, it is unlikely, based on present knowledge, that the low concentrations measured result in either APTF or trigeminal stimulation (cf. Emmen et al, ${ }^{102}$ Iregren $e t ~ a l^{105}$ ). It is possible, however, that access of VOCs to the corneal epithelium sensory receptors (nociceptors) would be increased by an APTF. ${ }^{15}$

An increase of the prevalence of eye complaints among asthmatic children has been associated with increased ozone concentrations and high temperature, including particles $(<13 \mu \mathrm{m}),{ }^{111}$ and eye irritation among subjects with obstructive airway disease has been found to be related to ozone levels. ${ }^{112}{ }^{113}$ Apparently, ionisation with negative ions relieved dry eye symptoms and increased the interblink interval in a hospital. ${ }^{114}$ It was hypothesised that the positive effect could be reduction of respirable particles. However, in a recent double blind crossover study at low levels in public office buildings, a $94 \%$ reduction of particles $(<3 \mu \mathrm{m})$ was not associated with reduced eye symptoms. ${ }^{47}$ Neither is there convincing evidence that indoor particles by mass, per se, are causative of eye symptoms, ${ }^{11}{ }^{107}$ except for special cases reported in a review. ${ }^{11}$

\section{CORRELATION BETWEEN PERCEIVED EYE COMPLAINTS AND ALTERATIONS OF THE PTF}

A number of office related eye complaints/disturbances (for example, occupational asthenopia, eye irritation, strained eye, visual fatigue, ocular discomfort, etc) have been reported in indoor field investigations. From a medical point of view, they have been characterised by specific symptoms/signs such as: burning, redness, gritty and itchy feeling, lacrimation, etc, and blurred vision, double vision, light intolerance, etc; however, information about location, duration, and onset is generally not reported, ${ }^{58}$ and neither is the use of certain medication, which acts as a confounding factor. ${ }^{24}$ Although positive associations with near work duration have been established, associations with the ophthalmic clinical picture are less clear. One reason for this is the wide range of "eye irritation" symptoms from mild to severe; for example, the "dry eyes" symptom appears only in certain indoor environments and generally under multifactorial conditions (as opposed to the disease "dry eyes"). Patients diagnosed with asthenopia of unknown aetiology may in fact have dry eyes. ${ }^{115}$ Dry air is another common complaint in indoor environments to consider. ${ }^{2}$ This may well be associated with eye complaints and not necessarily the RH, per se.

There appear to be many different mechanisms associated with the increase of office eye symptomatology (see table 2), which could either have the same origin (overlapping symptoms) or act synergistically. For example, a few studies have shown clusters of symptoms, such as "dryness, smarting, and itching" ${ }^{\prime 116}$ and "itching, irritating, grating, and sandy". ${ }^{117}$ One study has shown that "external symptoms", such as burning, irritation, tearing, and dryness were located in the front and inferior part of the eye, while "internal symptoms" comprised ache, pain, strain, and headache located behind the eyes. ${ }^{118}$ Among dry eye diagnosed patients, dryness and soreness were the most frequently reported symptoms of eye irritation. ${ }^{119}$

A number of identified correlations between reported eye symptoms and objective measures of an APTF, both in human exposure studies with indoor pollutants and in office investigations have been reported. ${ }^{11}$ However, there are also studies where such correlations are absent. ${ }^{6}{ }^{11}{ }^{160-122}$ This is comprehensible in view of both conceptual and perceptual overlap of reported symptoms. For example, it has been observed that occasional dry spots (observed by fluorescein staining of the PTF) occurred during the blink interval in about $50 \%$ of apparently normal patients. In less than $50 \%$ of patients with apparently normal eyes, dry spots were observed to occur consistently after blinking. ${ }^{86}$ Some of these patients with dry spots and epithelial alteration of conjunctiva (observed by lissamine green staining) neither blinked immediately after the spot formation nor expressed discomfort. Generally, however, the development of symptoms coincides with APTF more often than situations where it does not (for example,Wieslander et al; ${ }^{101}$ see also references in Wolkoff et $a l^{11}$ ). However, the observed location of dry spots may not correspond to the perceived location of symptoms such as smarting and stinging. ${ }^{123}$

Enhanced water loss and inadequate tear production lead ultimately to an APTF, hyperosmolarity, and corneal and conjunctival epithelial damage. This could obviously result in severe ocular/visual discomfort. For example, epithelial alteration of conjunctiva was significantly increased among female subjects carrying out typical office work for six hours in a simulated office environment (laser printer and photocopier) compared to exposure under similar, but clean environmental conditions. ${ }^{124}$ During their VDU work that included reading, it is likely that BF was reduced and OS enlarged, thus leading to a poor PTF redistribution and enhanced water loss. Indeed, reduced BF has been associated with reporting of increased discomfort, which further increased during exposure to high air velocity. ${ }^{27}$ The significant increase of reported dry eyes in the simulated office environment may thus be at least partially explained by enhanced PTF water loss. This has been confirmed in a study about VDU work in controlled environments of low $\mathrm{RH}^{125}$ (cf. Korb et al ${ }^{126}$ ). In addition, faster evaporation results in faster stimulation of cornea by cooling, which may be perceived as uncomfortable (that is, discomfort). However, the eyelids appear to be more sensitive than the cornea itself. ${ }^{127}$ Under these circumstances, the main cause of eye discomfort is increased activity of the sensory nociceptive terminals in the exposed OS. However, the discomfort experienced is unable to overcome the strong inhibition of involuntary and reflex blinking mechanisms during, for example, PC games/ tasks. 273971

It has been reported that the increase of the RH from 35\% to $43 \%$ had no effect on self-reported BUT (measured as the time before discomfort/pain is perceived after a blink with lids open), although the perception of dry air was reduced significantly ${ }^{128}$ ( $\mathrm{cf}$. Nagda et al ${ }^{129}$ ). One explanation could be that the increase of RH results in less water loss, possibly resulting in less cooling effect of the cornea. The above agrees with the observation that increased periocular RH resulted in a substantial increase of the thickness of the PTF that also relieved symptoms as a result of APTF; ${ }^{126}$ similarly, the use of glasses with side covers and moist inserts has a stabilising effect in dry eye patients by increasing the interblink time and reducing the blink duration. ${ }^{126} 130131$

It appears that the intensity of eye symptoms among office workers increases during a working day, ${ }^{84} 49$ and in particular for CL wearers in the evening. ${ }^{484967}$ 


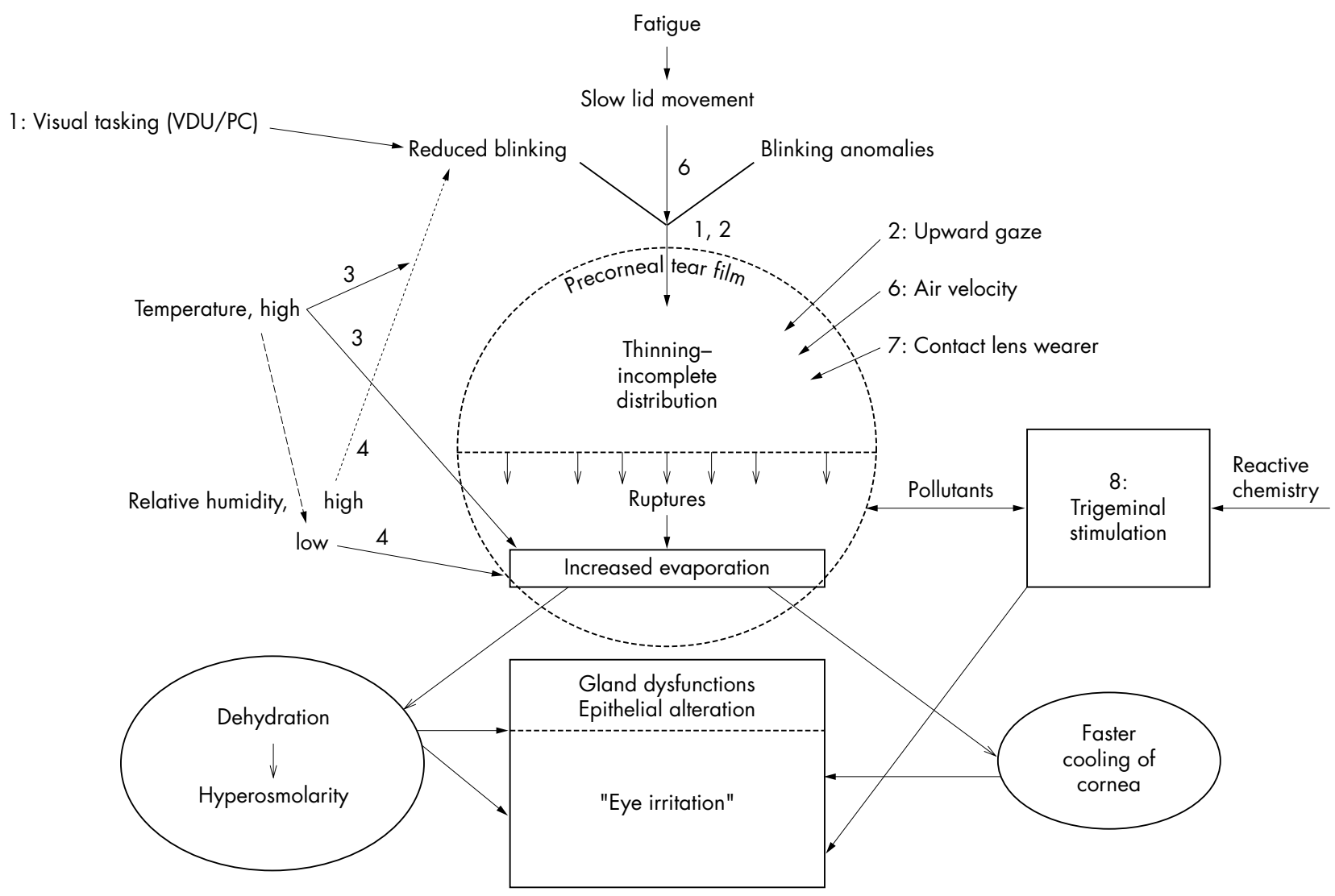

\footnotetext{
$\longrightarrow=$ Process leading to an effect: e.g. reduced eye blinking, incomplete distribution of PTF, increased water loss from the PTF. $\longleftrightarrow=$ Certain pollutants may also act through an altered PTF possibly with free nerve endings.

$\longrightarrow=$ Increased water evaporation leads to dehydration of the PTF and cooling of the cornea.

$--\rightarrow=$ Usually, high temperature reduces the relative humidity.

...... = High relative humidity may reduce the blink frequency.
}

Figure 1 Diagram of processes resulting in altered precorneal tear film (PTF), which leads to increased water loss, damage of the epithelial layer of the PTF, and gland dysfunctions. In addition, certain irritant pollutants including "reactive chemistry" (for example, certain oxidation products) may stimulate trigeminus of the outer eye.

Measurements showed some thinning of the LL in office workers during a working day. ${ }^{45}{ }^{50} 132$ One explanation for the eye symptomatology increase could be the less effective redistribution of the PTF as a result of the increased cognitive effort or difficult visual tasking that decreases the BF. Additional explanations for the eye symptomatology increase could be the overloading of accommodation and convergence, and poor lighting design. ${ }^{133}$ Moreover, psychological fatigue (drowsiness) results in a longer blink duration-that is, a slower eyelid opening, ${ }^{134}$ it has also been suggested that this kind of fatigue results in more blink incompleteness. ${ }^{135}$ Since the PTF is formed during the opening phase of a blink, the upper lid velocity determines the thickness-that is, a slower upper lid movement leads to a thinner PTF. ${ }^{23}$ Eventually, this will result in an enhanced APTF, which could result in ocular/ visual disturbances. Another explanation is additional water loss and reduction of the BF during a working day. ${ }^{47}$ Some authors have observed lower BUTs in warm and dry environments. ${ }^{44} 46$ The aqueous tear production also varies throughout the day, depending on stimuli through a reflex loop connecting the OS with the lacrimal glands ( $\mathrm{cf}$. Rolando and Zierhut $^{18}$ ). Likewise, the meibomian production has its maximum just after wakening. ${ }^{36}$
It is clear that the perception of eye symptoms during the initial period after entering an office environment depends on both the RH and the air quality of the outdoor environment experienced during commuting and reflected in the stability of the PTF (cf. Saxena et al, ${ }^{12}$ Paschides et $a l^{44}$ ). This is important to consider in experimental human exposure studies as well as in clinical examinations.

Finally, allergic conjunctivitis associated with decreased BUT and less goblet cell density, ${ }^{137}$ in addition to other APTF conditions, ${ }^{138}$ adds to the overall dry eye prevalence. ${ }^{66} 139$

\section{CONCLUSIONS}

The purpose of this review is to identify some of the environmental (for example, thermal, and chemical) factors that cause alterations to the eye, resulting in complaints in office-like environments.

There is a mechanistic dichotomy of eye complaints mediated through trigeminal stimulation by the action of certain irritating indoor pollutants and dry eyes, mediated through corneal stimulation by an APTF (see fig 1 ). However, it is still difficult to fully understand the aetiopathogenesis of symptoms, in that individual, environmental, and task related causes can be synergistically involved, in addition to 
the use of certain kinds of medication. There is no indication that indoor pollutants, neither chemically stable VOCs nor particles, by themselves, can alter the PTF and result in eye complaints. However, gas phase oxidation mixtures between ozone and certain, common, chemically reactive VOCs (alkenes, like terpenes) can produce eye irritants, specifically in office environments, in addition to the well known eye and upper airway irritants, like formaldehyde. The impact of eye irritants might be further exacerbated by an APTF; for example, by prolonged low $\mathrm{RH}$ or high room temperature (see below).

One alternative mechanism leading to perceived dried, tired, or irritated eyes is dehydration of the PTF, especially during work of high demand of visual tasking. Dehydration can occur by: (1) evaporative water loss; (2) tear composition deficiency - that is, gland dysfunctions, in particular meibomian $^{140}{ }^{141}$ and other lacrimal gland dysfunctions; and (3) blinking deficiency. Under these conditions, PTF is more prone to ruptures (that is, APTF), the severity of which increases with decreasing thickness. ${ }^{23}{ }^{70}$ Once local thinning has occurred, resistance to further thinning decreases. ${ }^{41}$ Thinning, ruptures, and dry spots eventually result in enhanced water evaporation that is dominated by external diffusion. Lastly, blink anomalies that alter the PTF redistribution, thus causing ruptures, further aggravate the clinical and subjective picture. Moreover, an APTF decreases the optical quality of the eye, because of corneal irregularities. ${ }^{20} 21$

Conditions that may lead to increase of eye complaints in the office environment due to dryness of the PTF as a result of unbalanced water loss, and possible excess cooling of cornea, and the presence of certain reactive chemicals (irritants), include the following, according to fig 1 :

(1) VDU work or other near work with visual or cognitive tasking that reduces the BF leading to APTF, thinning of the PTF, and dehydration through unbalanced water loss

(2) Upgaze direction, typical in VDU work, widens the OS exposure, consequently enhancing thinning and water loss

(3) A high periocular temperature reduces the BF and enhances unbalanced water loss-that is, dehydration

(4) Low periocular RH enhances water evaporation, leading to unbalanced water loss-that is, dehydration

(5) High periocular air velocity $(>1 \mathrm{~m} / \mathrm{sec}$ ) increases rapidly and consistently the water evaporation from OS, possibly also at lower velocities

(6) A slower upper lid movement caused by fatigue/drowsiness leads to an incomplete PTF distribution on the OS

(7) The use of CL alters the PTF profoundly and promotes the condition for water loss-that is, OS dehydration

(8) The presence of specific eye irritants formed in reactions between ozone and certain unsaturated organic compounds (for example, alkenes). Their effect may be exacerbated at conditions of APTF.

The hypothesis remains that an APTF facilitates the access of typical indoor pollutants, resulting in eye complaints and/ or OS irritation. Rather than chemically stable indoor organic pollutants being a cause of eye complaints, it appears more plausible that work related factors like VDU, including high temperature, low RH, demands of visual and cognitive tasking, and psychological fatigue, enhance the water loss leading to dehydration of the PTF. Unsaturated VOCs in the indoor environment that undergo oxidation reactions with ozone should be considered sources of irritation, in particular in low RH environments.
For individual preventive measures, maintenance of the physiological BF is important in order to keep the OS moist as well as retain the OS as small as possible by downward gaze. Regular voluntary (that is, conscious) complete or fast blinking exercises combined with breaks could also be beneficial, in particular when carrying out work of high demand of visual tasking. In addition, high room temperature and/or low RH should be avoided, while high periocular $\mathrm{RH}$ is beneficial, in particular for CL wearers suffering from dry eyes. CL wearers and subjects suffering from ocular surface pathologies, should be considered susceptible and offered a health surveillance programme according to Council Directive 270/EEC. A number of potential patients are probably overlooked in the clinic, because eye irritation may appear only under certain indoor environmental conditions and be absent during examination. In addition to better descriptors for eye irritation in both clinical and epidemiological work, future research should focus on occupational conditions of APTF in combination with indoor irritants.

\section{ACKNOWLEDGEMENTS}

The work was partially supported by The Danish Working Environment Council and Service Center (2001-25).

\section{Authors' affiliation}

P Wolkoff, J K Nøigaard, National Institute of Occupational Health, Copenhagen, Denmark

P Troiano, Department of Ophthalmology, Ospedale Maggiore IRCCS, Milan, Italy

B Piccoli, Department of Occupational Health, University of Milan-ICP Hospital, Milan, Italy

\section{REFERENCES}

1 Brightman HS, Moss N. Sick building syndrome studies and the compilation of normative and comparative values. In: Spengler JD, Samet JM, McCarthy JF, eds. Indoor air quality handbook. New York: McGraw-Hill, 2000:3.1-3.32.

2 Reijula K, Sunderman-Digert C. Assessment of indoor air problems at work with a questionnaire. Occup Environ Med 2004;61:33-8.

3 Bron AJ. Diagnosis of dry eye. Survey of Ophthalmology 2001;45:S221-6.

4 Albietz JM. Dry eye: an update on clinical diagnosis, management and promising treatments. Clinical and Experimental Optometry 2001;84:4-18.

5 Lemp MA. New strategies in the treatment of dry-eye states. Cornea 1999; 18:625-32.

6 Doughty MJ, Blades KA, Ibrahim N. Assessment of the number of eye symptoms and the impact of some confounding variables for office staff in non-air-conditioned buildings. Opthal Physiol Opt 2002;22:143-55.

7 Hedge A, Erickson A, Rubin G. Predicting sick building syndrome at the individual and aggregate levels. Environment International 1996:22:3-19.

8 Begley CG, Caffery B, Chalmers RL, et al. Use of dry eye questionnaire to measure symptoms of ocular irritation in patients with aqueous tear deficient dry eye. Cornea 2002;21:664-70.

9 Scullica L, Rechichi C. The influence of refractive effects on the appearance of asthenopia in subjects employed at videoterminals (epidemiological survey on 30.000 subjects). Bolletino et Oculistica 1989:68:25-48.

10 Jaakkola MS, Jaakkola JJK. Office equipment and supplies: a modern occupational health concern. Am J Epidemiol 1999;150:1223-8.

11 Wolkoff $P$, Skov $P$, Franck $C$, et al. Eye irritation and environmental factors in the office environment. Hypotheses, causes, and a physiological model. Scand J Work Environ Health 2003;29:411-30.

12 Saxena R, Srivastava S, Trivedi D, et al. Impact of environmental pollution on the eye. Acta Ophthalmol Scand 2003;81:491-4.

13 Versura P, Profazio V, Cellini $M$, et al. Eye discomfort and air pollution. Ophthalmologica 1999;213:103-9.

14 Norn MS. Pollution keratoconjunctivitis. Acta Ophthalmol 1992;70:269-73

15 Pepose JS, Ubels JL. The cornea. In: Hart WM Jr, eds. Adler's physiology of the eye. St Louis: Mosby, 1992:29-70.

16 Kiærgaard SK, Hodgson M. The assessment of irritation using clinical methods and questionnaires. AlHAJ 2001;62:711-16.

17 Guillon J-P. Current clinical techniques to study the tear film and tear secretions. The tear film: structure, function and clinical examination. Oxford: Butterworth-Heinemann, 2002:51-81.

18 Rolando $M$, Zierhut $M$. The ocular surface and tear film and their dysfunction in dry eye disease. Survey of Ophthalmology 2001;45:S203-10.

19 Lozato PA, Pisella PJ, Baudoin C. The lipid layer of the lacrimal tear film: physiology and pathology. Journal of France Ophthalmology 2001;24:643-58.

20 Albarrán C, Pons AM, Lorente A, et al. Influence of the tear film on optical quality of the eye. Contact Lens and Anterior Eye 1997;20:129-35. 
21 Tutt R, Bradley A, Begley C, et al. Optical and visual impact of tear break-up in human eyes. Investigative Ophthalmology \& Visual Science 2000;41:4117-23.

22 Piccoli B. A critical appraisal of current knowledge and future directions of ergophthalmology. Ergonomics 2003;46:384-406.

23 Wong H, Fatt I, Radke CJ. Deposition and thinning of the human tear film. Journal of Collodial and Interface Science 1996;184:44-51.

24 Craig JP. Structure and function of the preocular tear film. The tear film: structure, function and clinical examination. Oxford: ButterworthHeinemann, 2002:18-50.

25 Lemp MA, Wolfley DE. The lacrimal apparatus. In: Hart WM Jr, ed. Alder's physiology of the eye. St Louis: Mosby, 1992:18-28.

26 Sibony PA, Evinger C. Anatomy and physiology of normal and abnormal eyelid position and movement. In: Miller NR, Newman NJ, eds. Walsh \& Hoyt's clinical neuro-ophthalmology. Baltimore: Williams \& Wilkins, 1998:1509-92.

27 Acosta CM, Gallar J, Belmonte C. The influence of eye solutions on blinking and ocular comfort at rest and during work at video display terminals. Experimental Eye Research 1999;68:663-9.

28 Nakamori K, Odawara M, Nakajima K, et al. Blinking is controlled primarily by ocular surface conditions. Am J Ophthalmol 1997;124:24-30.

29 Feng $Y$, Simpson TL. Nociceptive sensation and sensitivity evoked from human cornea and conjunctiva stimulated by $\mathrm{CO}_{2}$. Investigative Ophthalmology \& Visual Science 2003;44:529-32.

30 Abelson MB, Holly FJ. A tentative mechanism for inferior punctate keratopathy. Am J Ophthalmol 1977;83:866-9.

31 Carney LG, Hill RM. The nature of normal blinking patterns. Acta Ophthalmol 1982;60:427-33.

32 Collins M, Seeto R, Campbell L, et al. Blinking and corneal sensitivity. Acta Ophthalmol 1989:67:525-31.

33 Freudenthaler N, Neuf H, Kadner G, et al. Characteristics of spontaneous eyeblink activity during video display terminal use in healthy volunteers. Graefe's Archives of Clinical Experimental Opthalmology 2003;241:914-20.

34 Tsubota K. Tear dynamics and dry eye. Progress in Retinal and Eye Research 1998; 17:565-96.

35 Monster AW, Chan HC, O'Connor D. Long-term trends in human eye blink rate. Biotelemetry and Patient Monitoring 1978;5:206-22.

36 Doughty MJ. Consideration of three types of spontaneous eyeblink activity in normal humans: during reading and video display terminal use, in primary gaze, and while in conversation. Optometry and Vision Science 2001;78:712-25.

37 Klenø J, Wolkoff P. Changes in eye blink frequency as a measure of trigeminal stimulation by exposure to limonene oxidation products, isoprene oxidation products, and nitrate radicals. Int Arch Occup Environ Health 2004;77:235-43.

38 Piccoli B, Braga M, Zambelli PL, et al. Viewing distance variation and related ophthalmological changes in office activities with and without VDUs. Ergonomics 1996;39:719-28.

39 Rocher P, Fatt I. Hydrogel contact lenses. Optometry Today, 1995 July, 35:18-22.

40 Golding TR, Bruce AS, Mainstone JC. Relationship between tear-miniscus parameters and tear-film breakup. Cornea 1997;16:649-61.

41 Miller KL, Polse KA, Radke CJ. Black-line formation and the "perched" human tear film. Curr Eye Res 2002;25:155-62.

42 Kay DLC, Heavner DL, Nelson PR, et al. Effects of relative humidity on nonsmoker response to environmental tobacco smoke. Proceedings of the 5th International Conference on Indoor Air Quality and Climate. Mortgage and Housing Corporation, OHtawa, Canada, 1990;1:275-280.

43 Tsubota K, Hata S, Mori A, et al. Decreased blinking in dry saunas. Cornea 1997; 16:242-4.

44 Paschides CA, Stefaniotou M, Papageorgiou J, et al. Ocular surface and environmental changes. Acta Ophthalmol Scand 1998;76:74-7.

45 Berke A. Blinking frequency and the thickness of the lipid layer. In: Sullivan DA, Stern JA, Dartt DA, Sullivan RM, Bromberg BB, eds. Lacirmal gland, tear film, and dry eye syndrome 3. New York: Kluwer Academic/ Plenum Publishers, 2002:513-16.

46 Smedbold HT, Ahlen C, Norbäck D, Hilt B. Sign of eye irritation in female hospital workers and the indoor environment. Indoor Air 2001;11:223-31.

47 Mendell MJ, Fisk WJ, Dong MX, et al. Indoor particles and symptoms among office workers: results from a double-blind cross-over study. Epidemiology 2002;13:296-304

48 Baird JC, Berglund B, Esfandabad HS. Longitudinal assessment of sensory reactions in eyes and upper airways of staff in a sick building. Environ Int 1994;20:141-60.

49 Skov P, Valbjørn O, Gyntelberg F, DISG. RådhusundersøgelsenIndeklima i kontorer. Copenhagen: Arbejdsmiljofondet, 1989:1-71.

50 Franck C. Fatty layer of the precorneal film in the 'office eye syndrome'. Acta Ophthalmol 1991;69:737-43.

51 Skov P, Valbiørn O, Pedersen BV, DISG. Influence of indoor air quality on the sick building syndrome in an office environment. Scand J Work Environ Health 1990;16:363-71.

52 Cain WS, Leaderer BP, Ginsberg GL, et al. Acute exposure to low-level methyl tertiary-butyl ether (MTBE): human reactions and pharmacokinetic response. Inhalation Toxicology 1996;8:21-48

53 Craig JP, Tomlinson A. Importance of the lipid layer in human tear film stability and evaporation. Optometry and Vision Science 1997;74:8-13

54 Mori A, Oguchi Y, Okusawa Y, et al. Use of high-speed, high-resolution thermography to evaluate the tear film layer. Am J Ophthalmol 1997; 124:729-35.
55 Murphy PJ, Patel S, Morgan PB, et al. The minimum stimulus energy required to produce a cooling sensation in the human cornea. Opthal Physiol Opt 2001;21:407-10.

56 Efron N, Young G, Brennan NA. Ocular surface temperature. Current Eye Research 1989;8:901-6.

57 Mathers WD, Daley TE. Tear flow and evaporation in patients with and without dry eye. Ophthalmology 1996;103:664-9.

58 Gilbard JP. Dry eye, blepharitis and chronic eye irritation:divide and conquer. Journal of Ophthalmic Nursing Technology 1999;18:109-15.

59 Tiffany JM, Winter N, Bliss G. Tear film stability and tear surface tension. Current Eye Research 1989;8:507-15.

60 Begley CG, Chalmers RL, Mitchell GL, et al. Characterization of ocular surface symptoms from optometric practices in North America. Cornea 2001;20:610-18.

61 Doughty MJ, Fonn D, Richter D, et al. A patient questionnaire approach to estimating the prevalence of dry eye symptoms in patients presenting to optometric practices across Canada. Optometry and Vision Science 1997;74:424-31.

62 Fonn D, Situ P, Simpsom T. Hydrogel lens dehydration and subjective comfort and dryness ratings in symptomatic and asymptomatic contact lens wearers. Optometry and Vision Science 1999;76:700-4

63 Vajdic C, Holden BA, Sweeney DF, et al. The frequency of ocular symptoms during spectacle and daily soft and rigid contact lens wear. Optometry and Vision Science 1999;76:705-11.

64 McDonald JE, Brubaker S. Miniscus-induces thinning of tear films. Am J Ophthalmol 1971;72:139-46.

65 Itoh R, Yokoi N, Kinoshita S. Tear film instability induced by rigid contact lenses. Cornea 1999;18:440-3.

66 Shimmura S, Shimazaki J, Tsubota K. Results of a population-based questionnaire on the symptoms and lifestyles associated with dry eye. Cornea 1999; 18:408-11.

67 Begley CG, Caffery B, Nichols KK, et al. Responses of contact lens wearers to a dry eye survey. Optometry and Vision Science 2000;77:40-6.

68 Nichols JJ, King-Smith PE. Thickness of the pre- and post-contact lens tear film measured in vivo by interferometry. Investigative Ophthalmology \& Visual Science 2003;44:68-77.

69 Hamano H, Hori M, Mitsunaga S. Measurement of evaporation rate of water from the precorneal tear film and contact lenses. Contacto 1981:7-14.

70 Creech JL, Do LT, Fatt I, et al. In vivo tear-film thickness determination and implications for tear-film stability. Current Eye Research 1998;17:1058-66.

71 Doughty MJ. Re-wetting, comfort, lubricant and moisturising solutions for the contact lens wearers. Contact Lens and Anterior Eye 1999;22:116-26.

72 Cederstaff TH, Tomlinson A. A comparative study of tear evaporation rates and water content of soft contact lenses. American Journal of Optometry \& Physiological Optics 1983:60:167-74.

73 Bron AJ, Tiffany JM, Yokoi N, et al. Using osmolarity to diagnose dry eye: a compartmental hypothesis and review of our assumptions. In: Sullivan DA, Stern ME, Tsubota K, Dartt DA, Sullivan RM, Bromberg BB, eds. Lacrimal gland, tear film, and dry eye syndrome 3. New York: Kluwer Academic/ Plenum Publishers, 2002:1087-95.

74 Albietz JM. Conjunctival histologic findings of dry eye and non-dry eye contact lens wearing subjects. CLAO Journal 2001;27:35-40.

75 Troiano P. The lacrimal tissue and the lacrimal lenses. Eur J Ophthalmol 2003;13:734.

76 Nilsson SEG, Andersson L. Contact lens wear in dry environments. Acta Ophthalmol 1986;64:221-5.

77 Glasson MJ, Stapleton F, Keay L, et al. Differences in clinical parameters and tear film of tolerant and intolerant contact lens wearers. Investigative Ophthalmology \& Visual Science 2003;44:5116-24.

78 Collins MJ, Stahmer D, Pearson G. Clinical findings associated with incomplete blinking in soft lens wearers. Clinical and Experimental Optometry 1989;72:55-60.

79 Ehlers N. The precorneal film. Acta Ophthalmol 1965;81(suppl):5-136.

80 Sharma A, Tiwari S, Khanna R, et al. Hydrodynamics of meniscus-induced thinning of the tear film. Advanced Experimental Medical Biology 1998;438:425-31

81 Guillon M, Styles E, Guillon J-P, et al. Preocular tear film characteristics of nonwearers and soft contact lens wearers. Optometry and Vision Science 1997:74:273-9.

82 Korb DR, Baron DF, Herman JP, et al. Tear film lipid layer thickness as a function of blinking. Cornea 1994;13:354-9.

83 Norn MS. External eye. In: Methods of examination. Copenhagen: Scriptor, 1983.

84 Bitton E, Lovasik JV. Longitudinal analysis of precorneal tear film rupture patterns. Advanced Experimental Medical Biology 1998;438:381-9.

85 Cho $P$, Brown B, Chan I, et al. Reliability of the tear break-up time technique of assessing tear stability and the locations of the tear break-up in Hong Kong Chinese. Optometry and Vision Science 1992;69:879-85.

86 Brown SI. Dry spots and corneal erosions. International Ophthalmology Clinic 1973;13:149-56.

87 Bruce AS, Mainstone JC, Golding TR. Analysis of tear film breakup on Etafilcon A hydrogel lenses. Biomaterials 2001;22:3249-56.

88 Rengstorff RH. The precorneal tear film: breakup time and location in normal subjects. American Journal of Optometry \& Physiological Optics 1974,51:765-9

89 Tomlinson A, Choon Thai L, Doane MG, et al. Reliability of measurements of tear physiology. In: Sullivan D, Stern ME, Tsubota K, Dartt DA, Sullivan RM, Bromberg BB, eds. Lacrimal gland, tear film, and dry eye syndromes 3. New York: Kluwer Avademic/Plenum Publishers, 2002:1097-105.

90 Nichols KK, Nichols JJ, Lynn MG. The relation between tear film tests in patients with dry eye disease. Opthal Physiol Opt 2003;23:553-60. 
91 Singh G, Bhinder HS. Closed chamber thermometry and humidity measurements in normal and dry eye patients: a pilot study. Eur $J$ Ophthalmol 2003; 13:343-50.

92 Efron N, Brennan NA. A survey of wearers of low water content hydrogel contact lenses. Clinical and Experimental Optometry 1988;71:86-90.

93 Tomlinson A, Cederstaff TH. Tear evaporation from the human eye. The effects of contact wear. Journal of British Contact Lens Association 1983;5:141-50.

94 Mathers WD, Lane JA, Sutphin JE, et al. Model for ocular tear film function. Cornea 1996;15:110-19.

95 Gilbard JP, Farris RL. Tear osmolarity, ocular surface disease in keratoconjunctivitis sicca. Arch Ophthalmol 1979;97:1642-6.

96 Craig JP, Singh I, Tomlinson A, et al. The role of tear physiology in ocular surface temperature. Eye 2000;14:635-41.

97 Mathers WD, Lane JA. Meibomian gland lipids, evaporation, and tear film stability. In: Sullivan DA, Dartt DA, Meneray MA, eds. Lacrimal gland, tear film, and dry eye syndromes 2. New York: Plenum Press, 1998:349-59.

98 Kuizenga A, van Haeringen NJ, Kiilstra A. Inhibition of hydroxyl radical formation by human tears. Investigative Ophthalmology \& Visual Science 1987;28:305-13.

99 Schmut O, Gruber E, el-Shabrawi Y, et al. Destruction of human tear proteins by ozone. Free Radical Biology \& Medicine 1994;17:165-9.

100 Kiærgaard SK, Mølhave L, Pedersen OF. Human reactions to indoor air pollutants: n-decane. Environment International 1989;15:473-82.

101 Wieslander G, Norbäck D, Lindgren T. Experimental exposure to propylene glycol mist in aviation emergency training: acute ocular and respiratory effects. Occup Environ Med 2001;58:649-55.

102 Emmen $\mathrm{HH}$, Muijser $\mathrm{H}$, Arts $\mathrm{JH}$, et al. Human volunteer study with PGME eye irritation during vapour exposure. Toxicol Lett 2003;140-141:249-59.

103 Nihlén A, Löf A, Johanson G. Controlled ethyl tertiary-butyl ether (ETBE) exposure to male volunteers II. Acute effects. Toxicol Sci 1998;46:143-50.

104 Nihlén A, Wålinder R, Löf A, Johanson G. Experimental exposure to methyl tertiary-butyl ether. II. Acute effects in humans. Toxicol Appl Pharmacol 1998; 148:281-7.

105 Iregren A, Löf A, Toomingas A, et al. Irritation effects from experimental exposure to n-butyl acetate. Am J Ind Med 1993;24:727-42.

106 Kiærgaard SK, Mølhave L, Pedersen OF. Human reactions to a mixture of indoor air volatile organic compounds. Atmospheric Environment 1991;25A:1417-26.

107 Schneider T, Sundell J, Bischof W, et al. EUROPART. Airborne particles in the indoor environment. A European interdisciplinary review of scientific evidence on associations between exposure to particles in buildings and health effects. Indoor Air 2003;13:38-48.

108 Wolkoff $P$, Nielsen GD. Organic compounds in indoor air-their relevance for perceived indoor air quality. Atmospheric Environment 2001;35:4407-17.

109 Satici A, Bitiren M, Ozardali I, et al. The effects of chronic smoking on the ocular surface and tear characteristics: a clinical, histological and biochemical study. Acta Ophthalmol Scand 2003;81:583-7.

110 Wieslander G, Norbäck D, Nordström K, et al. Nasal and ocular symptoms, tear film stability and biomarkers in nasal lavage, in relation to buildingdampness and building design in hospitals. Int Arch Occup Environ Health 1999;72:451-61.

111 Just J, Segala C, Sahraoui F, et al. Short-term health effects of particulate and photochemical air pollution in asthmatic children. Eur Respir J 2002;20:899-906

112 Higgins BG, Francis HC, Yates CJ, et al. Effects of air pollution on symptoms and peak expiratory flow measurements in subjects with obstructive airway disease. Thorax 1995:50:149-55.

113 Höppe P, Peters A, Rabe G, et al. Environmental ozone effects in different population subgroups. Int J Hygiene Environ Health 2003;206:505-16.

114 Wyon DP. Sick buildings and the experimental approach. Environ Technol 1992;13:313-22.

115 Toda I, Fujishima H, Tsubota K. Ocular fatigue is the major symptom of dry eye. Acta Ophthalmol 1993;71:347-52.

116 Aronsson G, Strömberg A. Work content and eye discomfort in VDT work. International Journal of Occupational Safety and Ergonomics 1995;1:1-13.

117 Baird JC, Berglund B, Berglund U, et al. Symptom patterns as an early warning signal of community health problems. Environ Int 1990;16:3-9.

118 Sheedy JE, Hayes JN, Engle J. Is all asthnopia the same? Optom Vis Sci 2003;80:732-9

119 Nichols KK, Begley CG, Caffery B, et al. Symptoms of ocular irritation in patients diagnosed with dry eye. Optometry and Vision Science 1999:76:838-44.

120 Schein OD, Tielsch JM, Munõz B, et al. Relation between signs and symptom of dry eye in the elderly. Ophthalmology 1997;104:1395-401.

121 Muzi G, Dell'Omo M, Abbritti G, et al. Objective assessment of ocular and respiratory alterations in employees in a sick building. Am J Ind Med 1998:34:79-88.
122 Smeets MAM, Mauté $C$, Dalton P. Acute sensory irritation from exposure to isopropanol (2-propanol) at TLV in workers and controls: objective versus subjective effects. Ann Occup Hyg 2002;46:359-73.

123 Begley CG, Renner D, Wilson G, et al. Ocular sensations and symptoms associated with tear break up. Adv Exp Med Biol 2002;506:1127-33.

124 Wolkoff $P$, Johnsen CR, Franck C, et al. A study of human reactions to office machines in a climatic chamber. J Exposure Anal Environ Epidemiol 1992;1(suppl):71-97.

125 Ousler GW, Gomes PJ, Cramptom HJ, et al. The effects of a lubricant eye drop on the signs and symptoms of computer vision syndrome (CVS) exacerbated in a controlled adverse environment. Poster 2847-B722. Investigative Ophthalmology \& Visual Science 1999;40(ARVO suppl).

126 Korb DR, Greiner JV, Glonek T, et al. Effect of periocular humidity on the tear film lipid layer. Cornea 1996;15:129-34.

127 Beuerman RW, Tanelian DL. Corneal pain evoked by thermal stimulation. Pain 1979;7:1-14

128 Norbäck D, Wieslander G, Nordström K, et al. The effect of air humidification on symptoms and nasal patency, tear film stability, and biomarkers in nasal lavage: a 6 weeks' longitudinal study. Indoor+Built Environment 2000;9:28-34.

129 Nagda NL, Hodgson M. Low relative humidity and air cabin air quality. Indoor Air 2001;11:200-14.

130 Farris RL. The diagnosis and management of the dry eye. J Ophthal Nurs Technol 1997; 16:164-74.

131 Tsubota K, Hata S, Okusawa Y, et al. Quantative videographic analysis of blinking in normal subjects and patients with dry eye. Arch Ophthalmol 1996; 114:715-20.

132 Norn MS. Dessiccation of the pre-corneal film. Acta Ophthalmol 1969;47:865-80.

133 Piccoli B Soci G, Zambelli PL. Photometry in the workplace: a rationale for a new method. Ann Occup Hyg 2004;48:29-38.

134 Caffier PP, Erdmann U, Ullsperger P. Experimental evaluation of eye-blink parameters as a drowsiness measure. Eur J Appl Physiol 2003;89:319-25.

135 Kaneko K, Sakamoto K. Spontaneous blinks as a criterion of visual fatigue during prolonged work on visual display terminals. Perceptual and Motor Skills $2001 ; 92: 234-50$

136 Bron AJ, Tiffany JM. The meibomian glands and tear film lipids. In: Sullivan DA, Dartt DA, Meneray MA, eds. Lacrimal gland, tear film, and dry eye 2. New York: Plenum Press, 1998:281-95.

137 Toda I, Shimazaki J, Tsubota K. Dry eye with only decreased tear break-up time is sometimes associated with allergic conjunctivitis. Ophthalmology 1995; 102:302-9.

138 Lobefalo L, D'Antonio E, Colangelo L, et al. Dry eye in allergic conjunctivitis: role of inflammatory infiltrate. International Journal of Immunopathology and Pharmacology 1999;12:133-7

139 Albietz JM. Prevalence of dry eye subtypes in clinical optometry practice. Optometry and Vision Science 2000;77:357-63.

140 McCulley JP, Shine WE. Eyelid disorders: The meibomian gland, blepharitis, and contact lenses. Eye \& Contact Lens 2003;29:S93-5.

141 Shimazaki J, Sakata M, Tsubota K. Ocular surface changes and discomfort in patients with meibomian gland dysfunction. Arch Ophthalmol 1995; 113:1266-70.

142 Cho P, Sheng C, Chan C, et al. Baseline blink rates and the effect of visual task difficulty and position of gaze. Current Eye Research 2000;20:64-70.

143 Bentivoglio AR, Bressman SB, Cassetta E, et al. Analysis of blink rate patterns in normal subjects. Movement Disorders 1997:1028-34.

144 Brookings JB, Wilson GF, Swain CR. Psychophysiological responses to changes in workload during simulated air traffic control. Biological Psychology 1996;42:361-77

145 Bauer LO, Strock BD, Goldstein R, et al. Auditory discrimination and the eyeblink. Psychophysiology 1985;22:636-41.

146 Tanaka Y, Yamaoka K. Blink activity and task difficulty. Perceptual and Motor Skills 1993;77:55-66.

147 Karson CN. Blinking. Bulletin Societé belge Opthalmology 1989;237:443-57.

148 Goldstein R, Walrath LC, Stern JA, et al. Blink activity in a discrimination task as a function of stimulus modality and schedule of presentation. Psychophysiology 1985;22:629-35.

149 Wood JG, Hassett J. Eyeblinking during problem solving: the effect of problem difficulty and internally vs externally directed attention. Psychophysiol Res 1983;20:18-20.

150 Karson CN, Berman KF, Donnelly EF, et al. Speaking, thinking, and blinking. Psychiatry Res 1981;5:243-6.

151 York M. Ong J, Roberts JW. Variation in blink rate associated with contact lens wear and task difficulty. American Journal of Optometry and Archives of American Academy of Optometry 1971;48:461-7.

152 Fatt I. Observations of tear film break up on model eyes. CLAO $1991 ; 17: 267-81$. 